\title{
Analysis of Site Amplification and Nonlinear Response Based on Ground Motion Records at MYGH10 Station in Japan
}

\section{Shiliang Zhang}

China Earthquake Administration Institute of Engineering Mechanics

Dongwang Tao

China Earthquake Administration Institute of Engineering Mechanics

\section{Quancai Xie}

China Earthquake Administration Institute of Engineering Mechanics

\section{Qiang Ma ( $\nabla$ maqiang@iem.ac.cn )}

China Earthquake Administration Institute of Engineering Mechanics https://orcid.org/0000-0002-

9768-5223

\section{Fuchen Wang}

China Earthquake Administration Institute of Engineering Mechanics

\section{Research Article}

Keywords: Fukushima earthquake, Spectral ratio method, Theoretical transfer function, P-wave vertical amplification, Site amplification factor, Nonlinear site response

Posted Date: December 8th, 2021

DOl: https://doi.org/10.21203/rs.3.rs-1122308/v1

License: (c) (1) This work is licensed under a Creative Commons Attribution 4.0 International License. Read Full License 


\title{
1 Analysis of site amplification and nonlinear response based on \\ 2 ground motion records at MYGH10 station in Japan
}

\author{
3 Shiliang Zhang ${ }^{1,2} \cdot$ Dongwang Tao $^{1,2} \cdot$ Quancai Xie $^{1,2} \cdot$ Qiang Ma $^{1,2^{*}} \cdot$ Fuchen $^{2}$ \\ 4 Wang ${ }^{1,2}$ \\ $5{ }^{1}$ Institute of Engineering Mechanics, China Earthquake Administration, Harbin 150080, \\ 6 China \\ $7 \quad{ }^{2}$ Key Laboratory of Earthquake Engineering and Engineering Vibration of China Earthquake \\ 8 Administration, Harbin 150080, China. \\ 9 Correspondence should be addressed to Qiang Ma; maqiang@iem.ac.cn
}

10 Acknowledgments We thank the National Institute of Disaster Prevention Science and 11 Technology (NIED) for providing data support for this study. The figures and diagrams in 12 this paper were created using the Python programming language and the GMT (Generic 13 Mapping Tools). The authors are grateful to Zhuoxin Wang for his suggestions during the 14 writing of the paper. This study was financially supported by the Scientific Research Fund of 15 Institute of Engineering Mechanics, China Earthquake Administration (Grant No. 2016A03), 16 National Key Research and Development Program of China (Grant No. 2017YFC1500802), 17 and National Natural Science Foundation of China (Grant No. U2039209, 5150082083).

\section{Abstract}

19 Strong horizontal ground motions with the peak ground acceleration (PGA) larger than 1400 gal were observed at Yamamoto (MYGH10) station during the February $2021 \mathrm{Mj} 7.3$ off the east coast of Honshu, Japan, Fukushima earthquake. Firstly, in this paper, we discussed and verified the theoretical assumptions of the "Nakamura" method under weak and strong ground motions. The site amplification factor of the MYGH10 station was estimated using the surface horizontal-vertical spectral ratio (HVSR) and the surface-to-borehole spectral ratio (SBSR), and the corrected $\mathrm{HVSR}_{\mathrm{C}}$, respectively. Meanwhile, the reasons for underestimating the site amplification factor when using HVSR were explained. The vertical amplification phenomenon of seismic $P$-wave in the high-frequency band was analysed under weak and strong ground motions. Secondly, we utilized HVSR, SBSR, and theoretical transfer function (TTF) based on the 1D wave propagation theory to study the nonlinear site response of MYGH10 station under the mainshock of the Fukushima earthquake and the historically weak and strong ground motions, respectively. The changes in frequencies and amplitudes of the spectral ratio curves when nonlinearities were occurring at the site were analysed and compared using the spectra ratio curves of weak ground motion records and TTF as references. Finally, the recovery of the site after strong nonlinearity was also evaluated by comparing the spectral ratio curves of aftershocks records. We found that the most significant amplification factor of the site increased from 7 to more than 10 , and the predominant frequency decreased from $10 \mathrm{~Hz}$ to $3.8 \mathrm{~Hz}$ under the mainshock of the Fukushima earthquake. The predominant frequency returned to the previous value within three days after the mainshock, but the amplification factor did not.

40 Keywords Fukushima earthquake - Spectral ratio method - Theoretical transfer

41 function - $P$-wave vertical amplification - Site amplification factor - Nonlinear site 42 response 
In engineering seismology, site conditions are one of the factors that leading to severe earthquake damage, and the geological conditions of near-surface sites play a significant role in damage distribution as well as in the observed ground motion records (Rong et al. 2017; Roca et al. 2008) and are an essential cause for seismic wave amplification at the surface. Research on site amplification and site nonlinearity effect under strong ground motion has been a hot topic. The commonly used methods for estimating site characteristics in the engineering field are mainly to obtain the thickness of the overlying soil layers on bedrock and the shear wave velocity of each soil layer through borehole exploration, and then to get the characteristics such as the predominant period of the site; however, the borehole exploration method has some limitations because of the high economic cost and the difficulty of construction in some particular sites.

The horizontal-to-vertical spectral ratio method (HVSR) was first proposed by Yutaka Nakamura, a Japanese scholar, in 1989. The academic community later named the method after him as "Nakamura" method, which was used initially for site characterization estimation from measured microtremor records as a technique to estimate the resonant frequency of engineering sites and the stie amplification factor (Nakamura 1989; Nakamura 2019). The amplification factor of the site soil layer, also called empirical transfer function, can be obtained based on the observed ground motion data, and the HVSR method has better economy and convenience than the traditional method of studying site characterization through borehole exploration. Therefore, the spectral ratio method has been favoured by many scholars since it was proposed and has been applied in many research fields. For example, Yamazaki and Ansary (1997) extended the "Nakamura" method to evaluate site characteristics and site classification using the spectral ratio of ground motion records, and they proved its rationality by verifying that the spectral ratio of horizontal and vertical velocity response spectra at the same site is not significantly affected by earthquake magnitude, epicentre distance, and source depth.

Kawase et al. $(2011,2018)$ proposed a new spectral ratio calculation formula based on the plane wave diffused field theory by the method of empirical Green's function and used it for site wave velocity structure inversion (Ducellier et al. 2013; Nagashima et al. 2014). Rong et al. (2018) and LI et al. (2020) successively obtained the site-specific wave velocity structure using the inversion of the HVSR method. Zhao et al. (2004) and JI et al. (2017) used the HVSR method for site classification studies. Wen et al. $(1994 ; 1995 ; 2006)$ and Yu et al. (1993) investigated the characteristics of the spectral ratio curve when the engineering site occurs nonlinear phenomena under strong ground motion using the spectral ratio method. Luo et al. (2019) studied the nonlinear characteristics of the site with HVSR spectral ratio using the Wenchuan mainshock, aftershock, and station microtremor records. Zhu et al. (2020a) comparatively studied the differences in identifying the site resonant frequencies using the Fourier amplitude spectrum and the response spectrum and suggested that the Fourier amplitude spectrum should be preferred in calculating the HVSR and that the frequency corresponding to the highest peak has a better performance than the first peak frequency in characterizing the linear site response.

Beresnev and Wen (1996) found that nonlinear behaviour became more pronounced when the acceleration peak value exceeded the threshold of 100 200 gal at the engineering site. The phenomenon of HVSR $<1$ may occur in some frequency bands, which Moro (2014) attributed mainly to the inversion of the wave velocity structure of the soil layer; that is, the wave velocity of the upper soil layer is higher than that of the lower soil layer. 
This paper conducted a series of studies around the MYGH10 station in KiK-net (Kiban Kyoshin Network, a strong-motion seismograph network in Japan). Based on the previous studies, the principle of the spectral ratio method was analyzed and discussed based on the historical earthquake records of the MYGH10 station; the theoretical transfer function of the site based on the one-dimensional multilayer soil model was obtained using the borehole drilling data of the station; the differences and consistencies between HVSR and SBSR, in terms of site amplification and site nonlinear response identification, were compared and analyzed under weak and strong ground motions. The characteristics of site nonlinear response were summarized to explain the strong nonlinear phenomena occurred at the MYGH10 station site under the Fukushima mainshock.

\section{Background}

101 An earthquake of magnitude Mj 7.3 occurred off the east coast of Honshu, Japan, on 102 February 13, 2021, at a hypocenter depth of $55 \mathrm{~km}$, with the epicentre located at $37.73{ }^{\circ} \mathrm{N}$, $103141.70{ }^{\circ} \mathrm{E}$. A total of 930 stations on KiK-net and K-NET (Kyoshin Network) recorded the 104 earthquake. Fig. 1 shows the distribution of PGA recorded at 82 stations within $150 \mathrm{~km}$ from the epicentre. The closest station to the epicentre is FKS005, $64 \mathrm{~km}$ from the epicentre, with a PGA value of 583.1 gal and an instrumental seismic intensity of 5.4. In contrast, MYGH10 station, located in Miyagi Prefecture, $75 \mathrm{~km}$ from the epicentre, recorded the maximum acceleration record of this earthquake, with the PGA at north-south component exceeding 1.4 $\mathrm{g}$ and the instrumental seismic intensity reaching 6.4 (Note: the maximum seismic intensity in Japan is 7). Fig. 2 shows the time history diagrams of the surface and borehole sixcomponent acceleration records of the Fukushima mainshock recorded at station MYGH10, and Fig. 3 shows the corresponding Fourier amplitude spectra of the borehole and surface acceleration records. In contrast, the PGA values recorded at the nearby stations around the MYGH10 station are lower, and we consider that the ground motions may be amplified at the MYGH10 station due to site condition.

Therefore, in this paper, we use the ground motion data recorded at this station over the years and classify them into weak and strong ground motions according to PGA $<100$ gal or PGA>100 gal, that is, events with PGA less than 100 gal are attributed to the "weak ground motions" and events with PGA over 100 gal are considered as the "strong ground motions." Meanwhile, we compare the discriminations between the curves of HVSR and that of SBSR. The characteristics of the spectral ratio curves of weak motion, strong motion and the Fukushima mainshock records were compared and analyzed. A total of 26 groups of weak ground motions records with PGA $<100$ gal recorded at MYGH10 station from March to June after the Fukushima mainshock and 16 groups of aftershocks records within three days after the mainshock were selected to compare and analyze the recovery of the site after strong nonlinearity. 


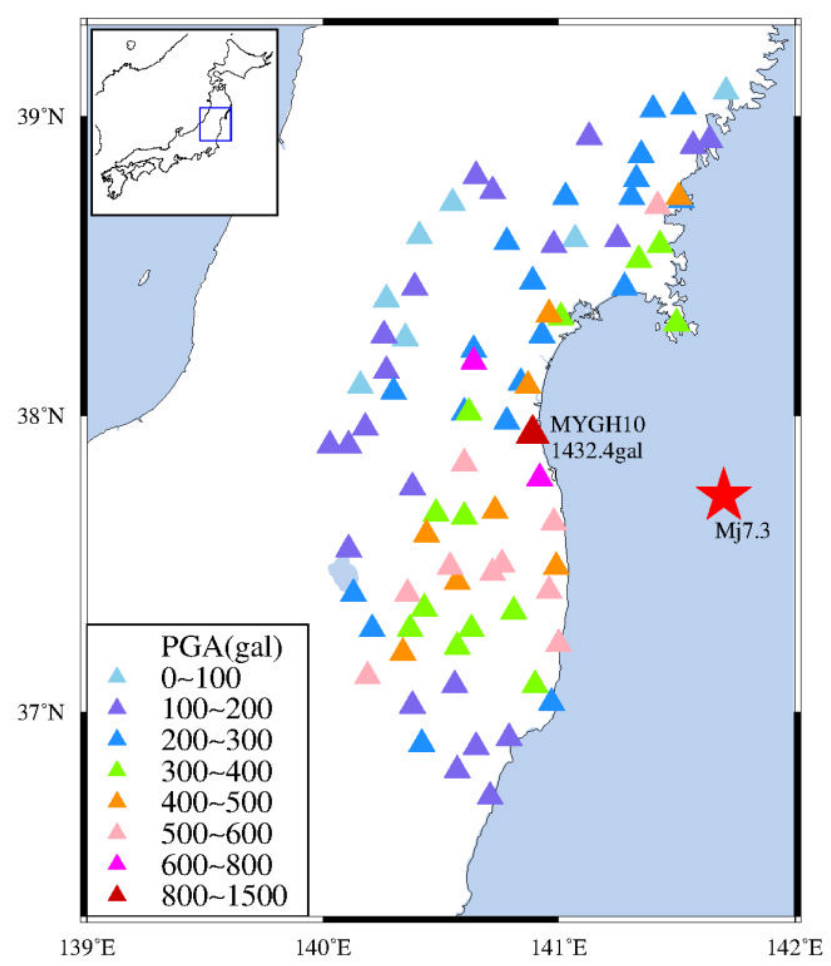

Fig. 1 Location of the Fukushima earthquake epicentre and PGA distribution of stations within $150 \mathrm{~km}$ from the epicentre (KiK-net, K-NET)

128
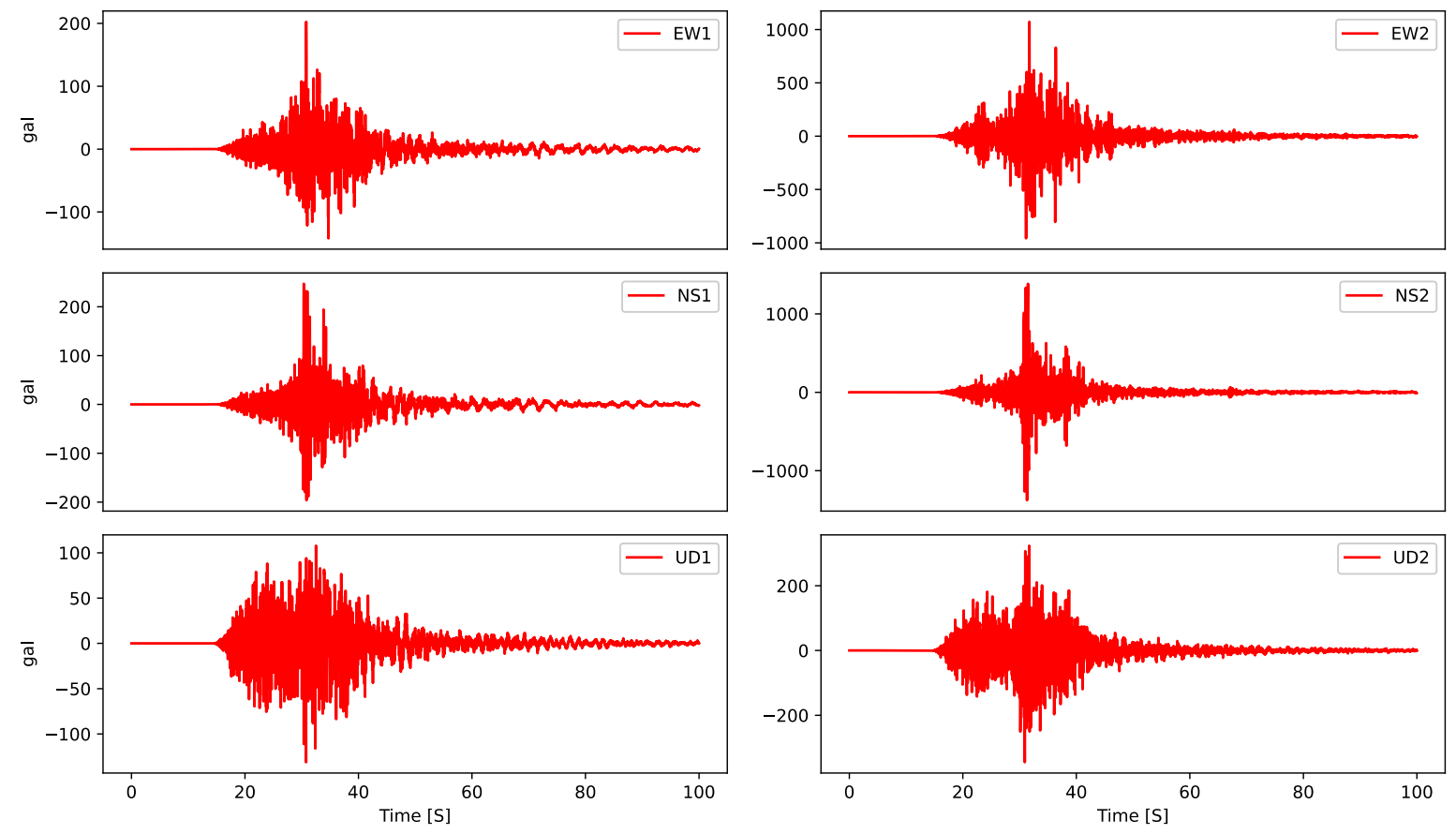

(a)

(b)

Fig. 2 Time history diagrams of three-component acceleration records at borehole (a) and surface (b) of the Fukushima mainshock 


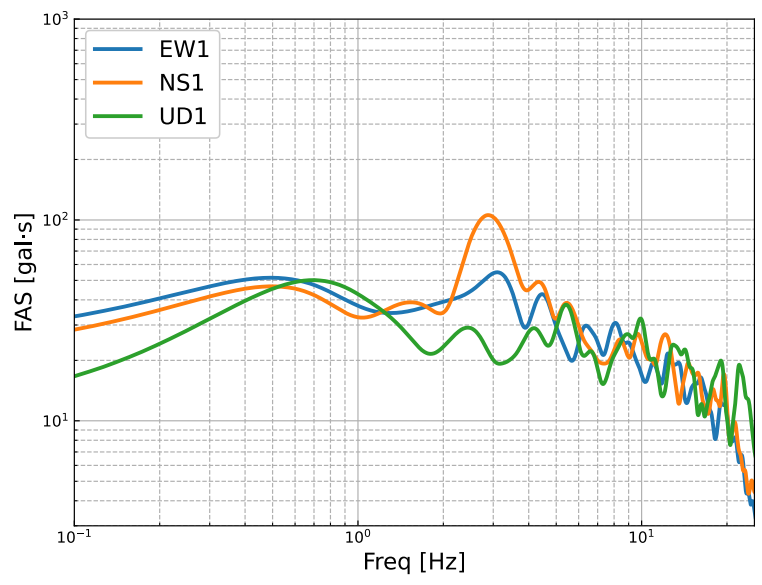

(a)

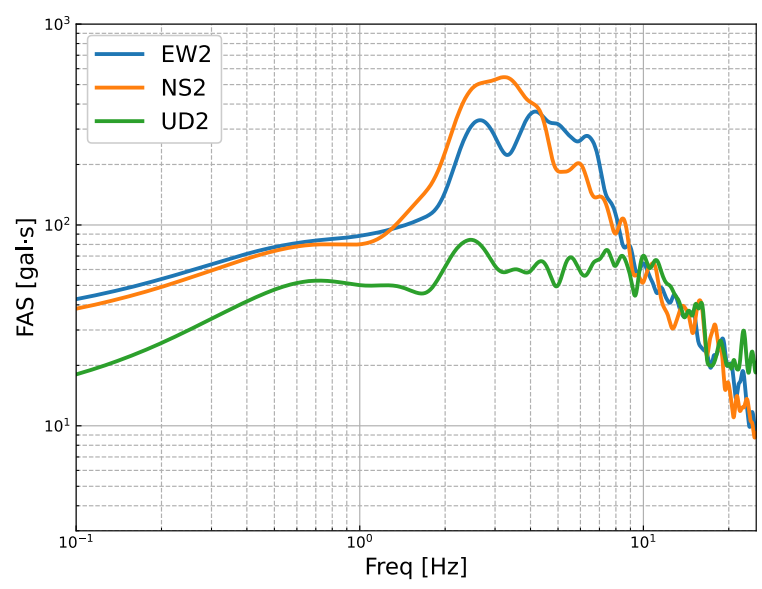

(b)

Fig. 3 Fourier amplitude spectra of three-component acceleration records at borehole (a) and surface (b) of the Fukushima mainshock

\section{Data}

132 The data in this paper were downloaded from the Strong-motion Seismograph Networks in Japan, and the seismic acceleration records were all recorded by the MYGH10 station, which is located in Miyagi Prefecture, Japan, at $37.94^{\circ} \mathrm{N}$ and $140.89^{\circ} \mathrm{E}$, and has a complete set of surface and borehole records and site conditions drilling data. When performing acceleration records selection, the PGA value of 100gal was used as the threshold value to distinguish strong and weak ground motions. The 2923 sets of ground motion records (excluding the records of the 2011 Tohoku earthquake) were downloaded from KiK-net for the period 20002021, of which 2891 sets have a PGA less than 100 gal and 32 sets have a PGA greater than $100 \mathrm{gal}$; the records of 16 aftershocks occurred within three days after the mainshock of the Fukushima earthquake was selected; we also used the records of the Fukushima mainshock and the 26 sets of records with PGA<100 gal between March and June after the mainshock, which is summarized in Table 1. The Fourier amplitude spectrum was obtained by Fast Fourier transform and then smoothed with a Parzen window function of $0.2 \mathrm{~Hz}$ in order to eliminate the inconvenience of identifying the predominant frequency and amplification caused by the burr in the Fourier spectrum. Fig. 4 shows the Fourier amplitude spectra of borehole and surface acceleration records with PGA>100 gal (see Fig. 4a Fig. 4f) and with PGA $<100$ gal (see Fig. 4 g Fig. 4l).

In the calculation of the spectral ratio, we use the complete acceleration waveform records, and the $H(f)$ and $V(f)$ terms in $H V S R(f)=\frac{H(f)}{V(f)}$ are calculated by equations (1) and (2), respectively:

$$
\begin{gathered}
H(f)=\sqrt{\left(E W^{2}+N S^{2}\right) / 2} \\
V(f)=U D
\end{gathered}
$$

where $E W, N S$, and $U D$ are the Fourier amplitude spectra of the acceleration, respectively. The surface and borehole spectral ratios are calculated by the equations (3) and (4):

$$
\begin{aligned}
& \operatorname{SBSR}_{S}(f)=\frac{\sqrt{E W_{2} \cdot N S_{2}}}{\sqrt{E W_{1} \cdot N S_{1}}} \\
& \operatorname{SBSR}_{P}(f)=\frac{\sqrt{U D_{2}}}{\sqrt{U D_{1}}}
\end{aligned}
$$




$$
S=\sqrt{\frac{\sum_{i=1}^{n}\left(x_{i}-\bar{x}\right)^{2}}{n-1}}
$$

160 to calculate the standard deviation of the spectral ratio values, where $\bar{x}$ is the sample mean

161 value. By the way, 100 gal is taken as the PGA boundary value of weak and strong motions, 162 during data selection, and weak ground motion records require all six components to meet 163 PGA $<100$ gal, while just only one of the six components should satisfy PGA $>100$ gal for 164 strong ground motion records.

165

166 Table 1 Ground motion records of MYGH10 station used in this study

\begin{tabular}{ccc}
\hline Time & PGA (gal) & Number of records (group) \\
\hline 2000.1.1 2021.1.1 & $<100$ & 2891 \\
\cline { 2 - 3 } (Note: not including the data of 2011) & $>100$ & 32 \\
\hline 2021.2 .13 & $=1432.4$ & 1 \\
$2021.2 .13 \sim 2021.2 .15$ & $4.0 \sim 97.2$ & 16 \\
$2021.3 \sim 2021.6$ & $<100$ & 26 \\
\hline
\end{tabular}

167

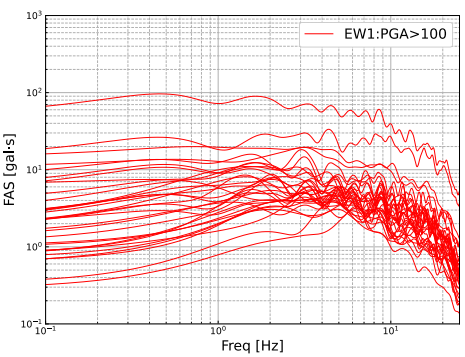

(a)

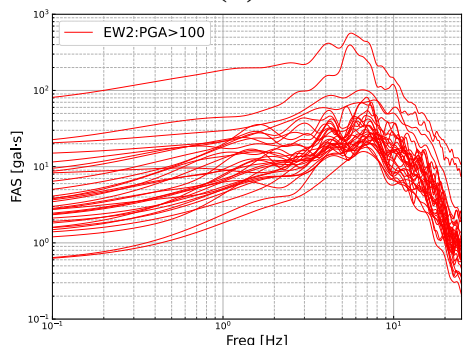

(d)

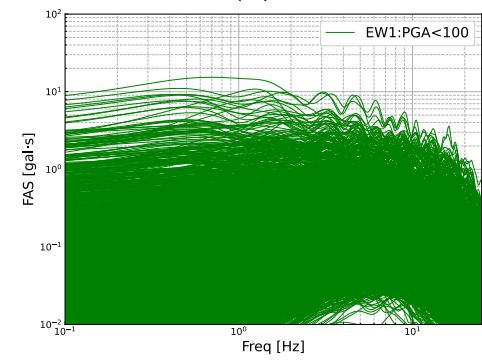

(g)

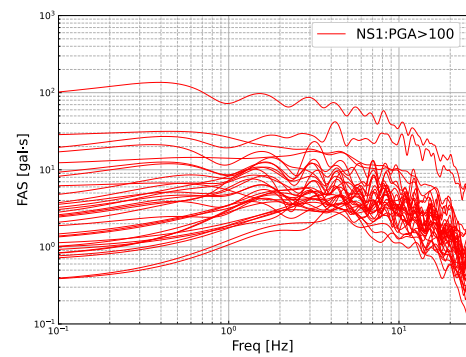

(b)

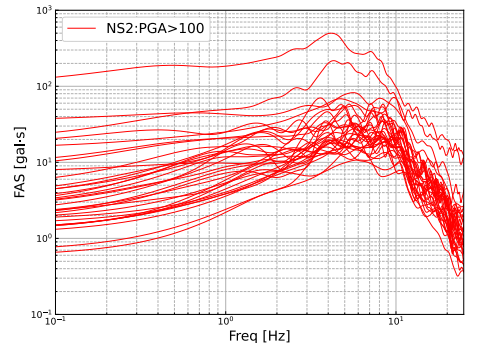

(e)

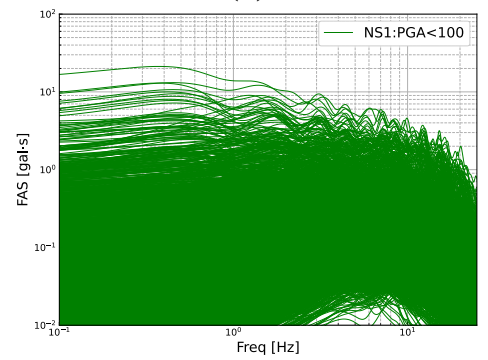

(h)

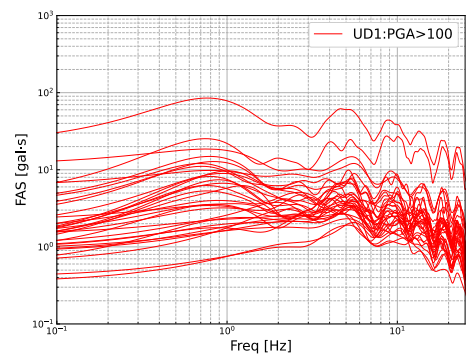

(c)

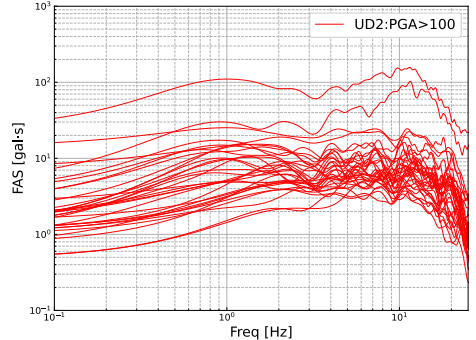

(f)

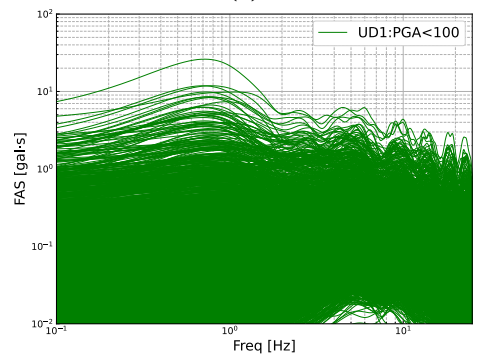

(i) 


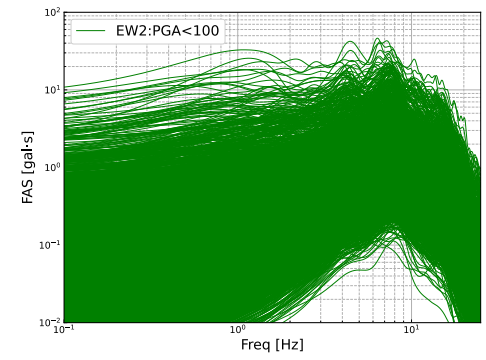

(j)

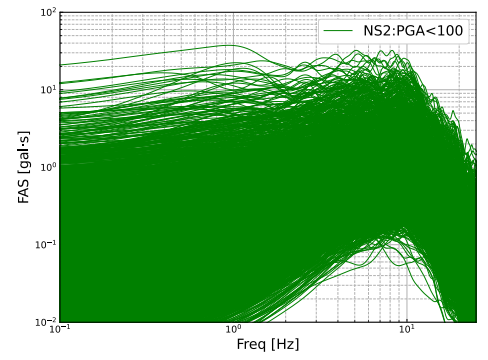

(k)

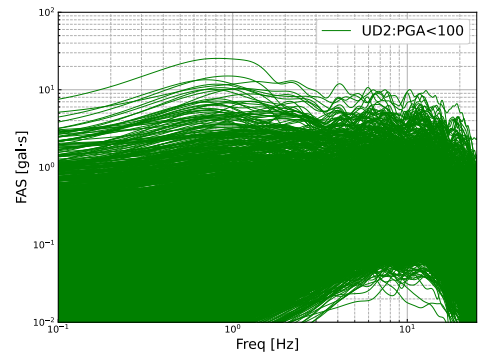

(l)

Fig. 4 Fourier amplitude spectra of six-component acceleration records at the surface and borehole for PGA $>100$ gal $(\mathbf{a} \sim \mathbf{f})$ and PGA $<100$ gal $(\mathbf{g} \sim \mathbf{l})$

\section{Method}

\subsection{Empirical Transfer Function (ETF)}

The spectral ratio method (HVSR), first proposed by Nakamura, was initially used to determine the predominant period of a site from measured microtremor data and later used to study the site amplification effect based on two assumptions: the first assumption is that the propagation of seismic waves at bedrock is even in all directions and is not amplified in both vertical and horizontal directions, i.e., $H_{B}=V_{B}$ and $H V S R_{B}=1$ at bedrock; the second assumption is that the soil layer does not amplify the seismic $P$-wave during the vertical propagation (Nakamura 1989; Lermo and Chavez-Garcia 1993), that is $V_{S}=V_{B}$ and $S B S R_{P}=1$, and the above $H$ and $V$ denote the horizontal and vertical components of ground motion, respectively. The subscript $S$ is the abbreviation of surface, and subscript $B$ is the abbreviation of bedrock.

As defined by Nakamura (1989), the transfer function from the surface to the bedrock in the horizontal direction is given by the following equation (6):

$$
\operatorname{SBSR}_{S}(f)=\frac{H_{S}(f)}{H_{B}(f)}
$$

Equation (6) above represents the horizontal amplification of the $S$-wave, where $H_{S}(f)$ and $H_{B}(f)$ represent the Fourier amplitude spectra of the horizontal components of ground motion at the surface and bedrock, respectively.

To reduce the effect of surface Rayleigh waves on the horizontal component $H_{S}(f)$, we can obtain the surface HVSRs through dividing equation (6) above by $V_{S} / V_{B}$ (Nakamura 1989; Nakamura 2019):

$$
\operatorname{HVSR}_{S}(f)=\frac{H_{S}(f)}{H_{B}(f)} / \frac{V_{S(f)}}{V_{B}(f)}=\frac{H_{S}(f)}{V_{S}(f)} / \frac{H_{B}(f)}{V_{B}(f)}=\frac{H_{S}(f)}{V_{S}(f)} / \operatorname{HVSR}_{B}=\frac{H_{S}(f)}{V_{S}(f)}
$$

Equation (7) is $\mathrm{H} / \mathrm{V}$, and the transformation of equation (7) yields the following equation (8) (Zhu et al. 2020a; 2020b):

$$
\operatorname{HVSR}_{S}(f)=\frac{H_{S}(f)}{H_{B}(f)} \times \frac{H_{B}(f)}{V_{B}(f)} \times \frac{V_{B(f)}}{V_{S}(f)}=\frac{H V S R_{B}(f)}{S B S R_{P}(f)} \times S B S R_{S}(f)
$$
where $\operatorname{SBSR}_{P}(f)$ is the surface-to-borehole spectral ratio in the vertical direction, representing the vertical amplification of the $P$-wave.

Fig. 5 shows the HVSR at bedrock for PGA $<100$ gal (see Fig. 5a) and PGA $>100$ gal (see Fig. 5b). It is found that although the frequencies of the peaks and troughs of the two curves are affected by the intensity of ground motion, the fluctuation range of their amplitudes does not change much. It is proved that the ground motion is in general not amplified at the bedrock and is not affected by the intensity of ground motion, so it can be approximated that $\operatorname{HVSR}_{B}(f)=1$, so equation (8) can be written as follows: 


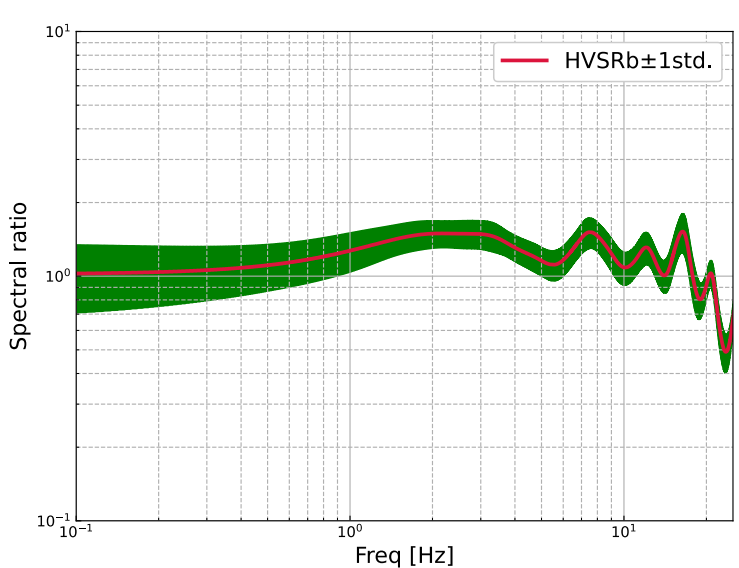

(a)

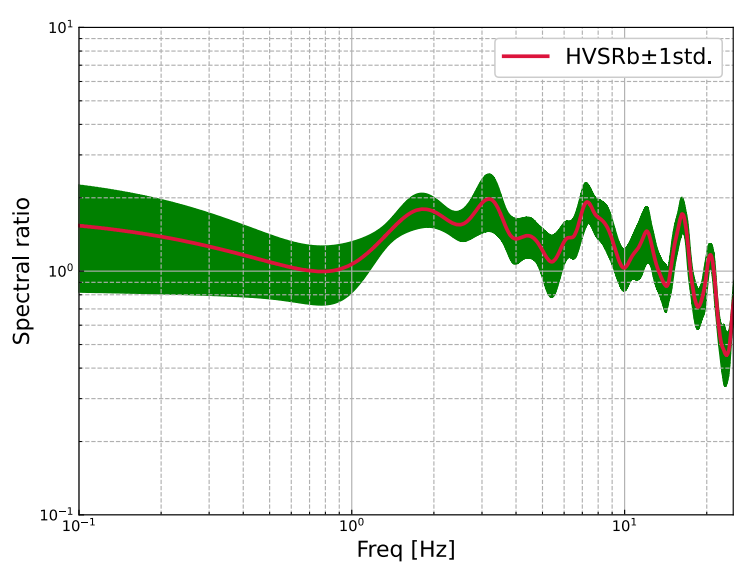

(b)

Fig. 5 HVSR at bedrock for PGA $<100$ gal (a) and PGA $>100$ gal (b). The solid red line represents the average spectral ratio curve of historical weak and strong ground motion records, and the widths of the spectral ratio curves represent \pm one standard deviation (1std)

203

204

205

206

207

208

209

210

According to the second assumption of the "Nakamura" method, the $P$-wave will not be amplified during the propagation of the soil layer, i.e. $\operatorname{SBSR}_{P}(f)=1$, which can be obtained by substituting into equation (9):

$$
\operatorname{SBSR}_{S}(f)=\operatorname{HVSR}_{S}(f)
$$

So it is considered that $\operatorname{HVSR}_{S}(f)$ can be used instead of $\operatorname{SBSR}_{S}(f)$ to represent the horizontal amplification of the $S$-wave.

We compare the differences in frequency bands and amplitude between the two spectral ratio curves under the weak and strong motions. Fig. 6 shows the spectral ratio curves for PGA $<100$ gal (see Fig. 6a) and PGA $>100$ gal (see Fig. 6b). However, the amplitude of $S B S R_{S}$ has been higher than that of $H V S R_{S}$ in the whole frequency range, and this phenomenon is more obvious after the predominant frequency of $8 \mathrm{~Hz}$, and the spectra ratio value of $H V S R_{S}$ is about 3 at $10 \mathrm{~Hz}$, while the corresponding value of $S B S R_{S}$ reaches 7 . In Fig. 6b, under the strong ground motions of PGA>100 gal, the amplitude of $\mathrm{HVSR}_{S}$ is slightly higher than that of $\mathrm{SBSR}_{\mathrm{S}}$ in the low-frequency band $0.1 \sim 0.35 \mathrm{~Hz}$. However, the amplitude of $\mathrm{SBSR}_{\mathrm{S}}$ is higher than that of $\mathrm{HVSR}_{\mathrm{S}}$ in the subsequent frequency bands, especially in frequency band $4 \sim 40 \mathrm{~Hz}$. Those mentioned above are consistent with previous studies that HVSR will underestimate the horizontal amplification of $S$-wave in the highfrequency band. 


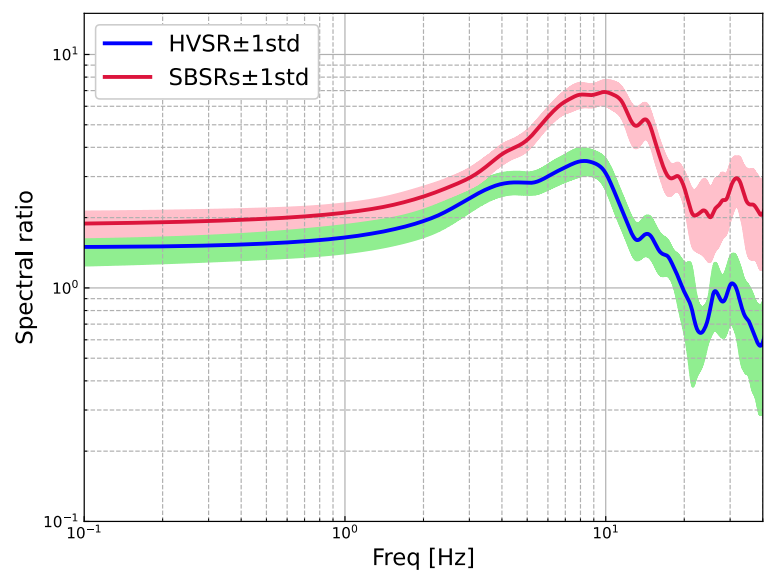

(a)

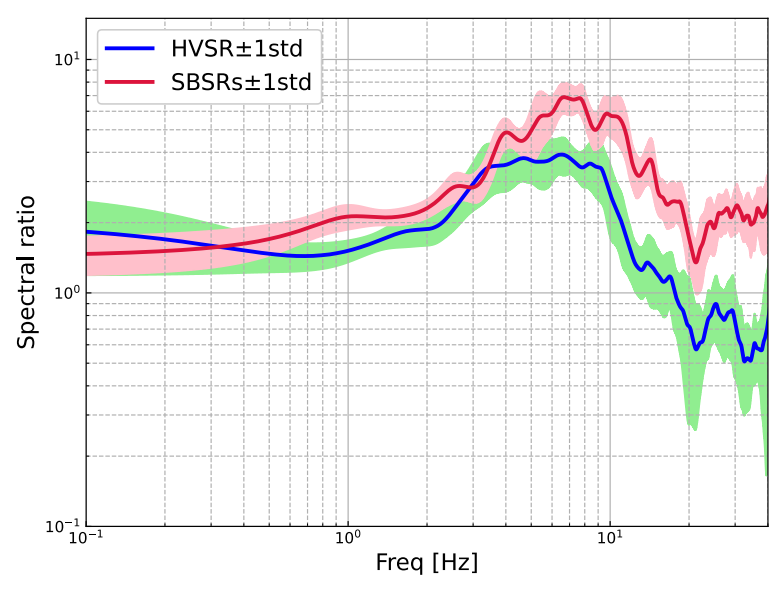

(b)

Fig. 6 HVSR and $\mathrm{SBSR}_{\mathrm{S}}$ for PGA $<100$ gal (a) and PGA $>100$ gal (b). The solid red and blue lines represent the average spectral ratio curves of historical weak and strong ground motion records, and the widths of the spectral ratio curves represent \pm one standard deviation (1std). Note: In order to highlight the difference between the curves of HVSR and SBSR $_{S}$ in the high-frequency band, we show the spectral ratio curves until $40 \mathrm{~Hz}$ in this figure

It is generally believed that the underestimation phenomenon occurs because the traditional "Nakamura" method ignores the vertical amplification of $P$-wave during propagation and simply assumes $S B S R_{P}=1$, while the observation data find that $S B S R_{P}=1$ does not hold true, as shown in Fig. 7a and Fig. 7b. The vertical amplification of $P$-wave relative to bedrock at either weak or strong motion is quite obvious, especially in the highfrequency band. For the MYGH10 station studied in this paper, the amplification factor in the range of $6 \sim 22.5 \mathrm{~Hz}$ is more than 2, and the spectral ratio value at the predominant frequency is as high as 4 .

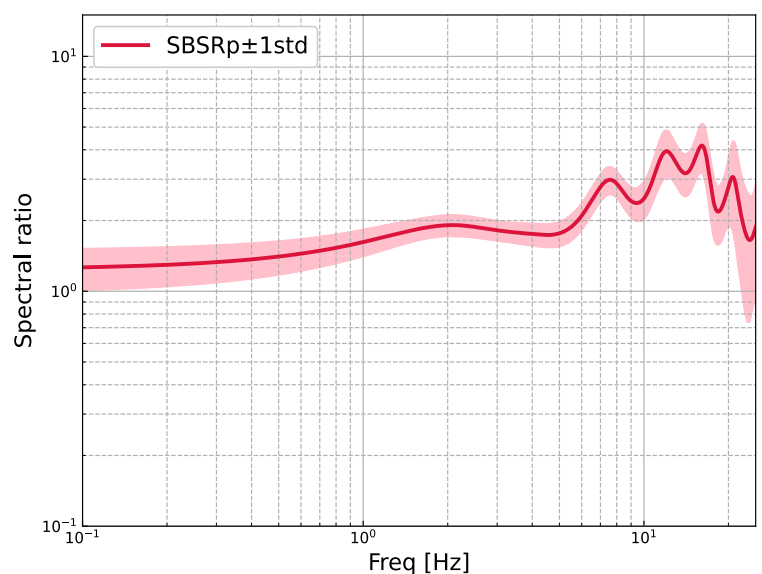

(a)

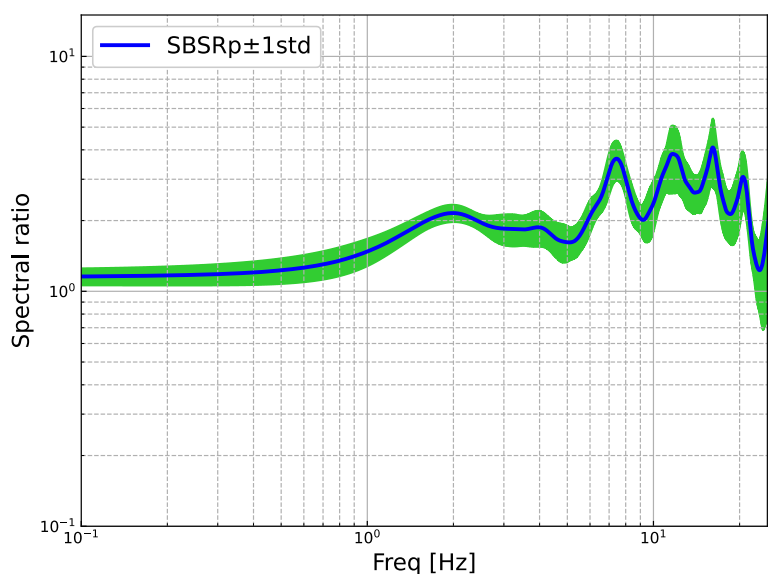

(b)

Fig. 7 Comparison of vertical amplification of $P$-wave for PGA $<100$ gal (a) and PGA $>100$ gal (b). The solid lines represent the average spectral ratio curves of historical weak and strong ground motion records, and the widths of the spectral ratio curves represent \pm one standard deviation $(1 \mathrm{std})$

In addition, the comprehensive comparative analysis of Fig. 7a and Fig. 7b shows that in the lower frequency band of $0.1 \sim 6 \mathrm{~Hz}$, the $\mathrm{SBSR}_{\mathrm{P}}$ values are smaller, fluctuating roughly in the range of 1.0 2.0, and the vertical amplification is not significant. Meanwhile, the HVSR and SBSR $_{S}$ values in Fig. 6 are also closer in this frequency band, so for the study of the 
amplification in the frequency band $0.1 \sim 6 \mathrm{~Hz}$ at the MYGH10 site, the HVSR is a good substitute for the SBSR $_{S}$.

From the above analysis, it can be tentatively concluded that the vertical amplification of seismic $P$-wave propagation in the soil layer cannot be neglected when using the HVSR method for site amplification studies; the vertical amplification of $P$-wave when propagating in the soil layer, and the underestimation of amplification by HVSR method are not overly affected by the intensity of ground motions; HVSR can be an ideal substitute for $\mathrm{SBSR}_{\mathrm{S}}$ in the frequency range of $0.1 \sim 6 \mathrm{~Hz}$.

So why does the vertical propagation of the $P$-wave affect the horizontal amplification of the $S$-wave? Parolai et al. (2004) and Zhu et al. (2020b) suggested that the vertical amplification is related to the propagation of the longitudinal wave ( $P$-wave), which are mainly derived from the conversion of non-vertical propagating $S v$ waves at the main layer interface, and the wave pattern conversion of $S v-P$ waves at the soil interface transfers the wave energy to the vertical direction. This causes the wave energy to decrease in the horizontal direction and increase in the vertical direction, which is reflected in the equation $H V S R=\frac{H}{V}$ as the horizontal spectral amplitude represented by $H$ decreases and the vertical spectral amplitude represented by $V$ increases so that the HVSR (H/V) decreases and eventually leads to the underestimation of the horizontal amplification of $S$-wave.

In order to more accurately estimate the horizontal amplification of $S$-wave by the soil layer, it is extremely important to consider the $\operatorname{SBSR}_{P}(f)$, that is, the vertical amplification of $P$-wave and the corrected horizontal amplification formula can be obtained from equation (9):

$$
\operatorname{HVSR}_{C}(f)=\operatorname{SBSR}_{S}(f)=\operatorname{HVSR}_{S}(f) \times \operatorname{SBSR}_{P}(f)
$$

Equation (11) shows that the horizontal amplification factor in the frequency domain for a given site can be directly derived by multiplying SBSR $_{P}$ to correct for the HVSRs.

In order to verify the correctness of the corrected $S$-wave horizontal amplification formula, we used the ground motion records of the MYGH10 station to get $\operatorname{HVSR}_{S}(f)$, $S B S R_{P}(f)$, and $S B S R_{S}(f)$, respectively, and then compared the two curves of $S B S R_{S}(f)$ and $\operatorname{HVSR}_{C}(f)$, and the results are shown in Fig. 8a and Fig. 8b. It is found that the spectral ratio curves after compensation correction improve the previous underestimation phenomenon very well, and it can be seen that the three spectral ratio curves before and after correction have the same shape trend and dominant frequency, and the corrected $\mathrm{HVSR}_{\mathrm{C}}$ curve is closer to $\mathrm{SBSR}_{S}$, especially in the high-frequency band, which indicates that the correction method can effectively improve the underestimation phenomenon of HVSR, and proves the vertical amplification of $P$-wave in the high-frequency band at the same time.

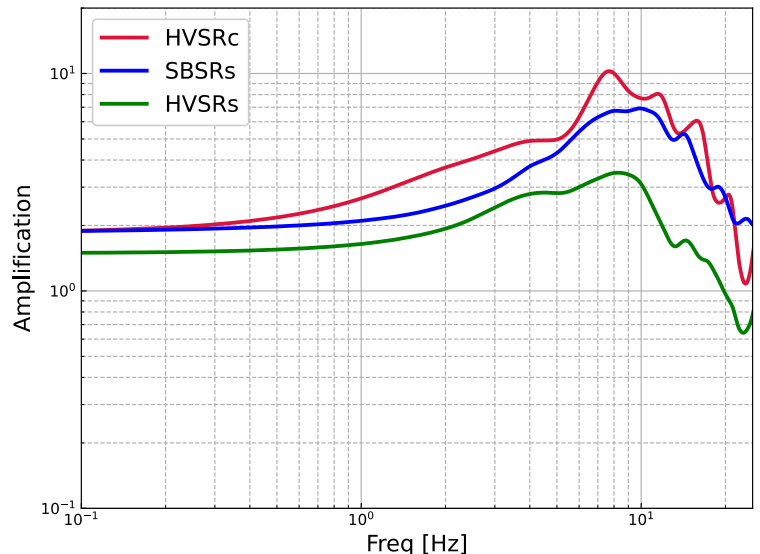

(a)

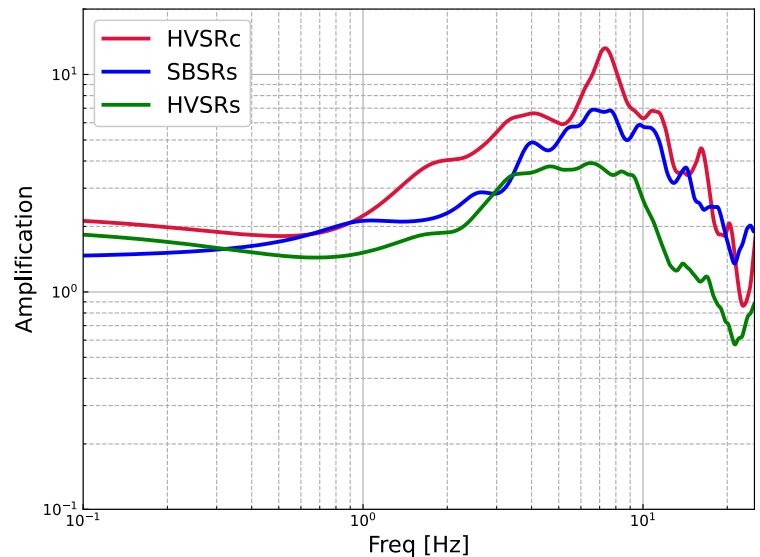

(b) 
Fig. 8 Comparison of three mean spectral ratio curves for PGA $<100$ gal (a) and PGA $>100$ gal (b). The solid lines represent the average spectral ratio curves of historical weak and strong ground motion records

It should be noted that although the corrected $\mathrm{HVSR}_{\mathrm{C}}$ can well improve the underestimation that occurs in the site amplification estimation when using $\mathrm{HVSR}_{\mathrm{S}}$, equation (11) still has some limitations, i.e., it is only applicable for station with complete surface and borehole array records, so the correction method is not applicable for station without borehole records. For this reason, Kawase et al. (2018) and Zhu et al. (2020b) successively proposed universal SBSRp instead of site-specific SBSRp to correct HVSRs for direct estimation of surface horizontal amplification. In this paper, our research object, station MYGH10, has complete surface and borehole records, so only the equation (11) was used for the study.

\subsection{Theoretical Transfer Function (TTF)}

285

286

287

288

289

290

291

For the multi-layered soil model with a horizontally layered site, the upper soil layer of bedrock can be divided into $\mathrm{N}$ layers according to its physical properties, and below the bedrock can be considered an infinite half-space (see Fig. 9). According to Snell's law, the incident angle of seismic waves propagating upward from the source to the bedrock will keep getting smaller, so the seismic waves at the bottom of the bedrock can be considered vertically incident shear waves (Yuan and Tian 2012).
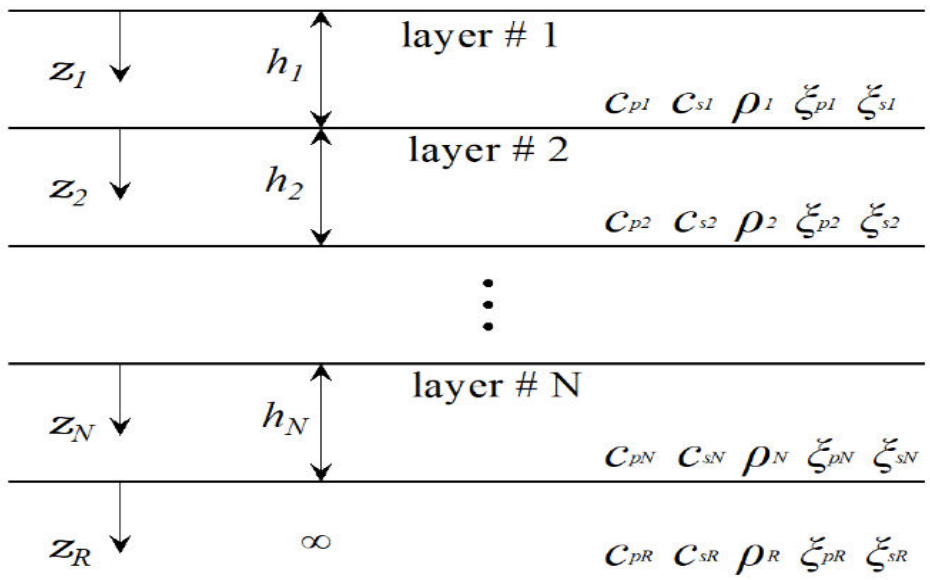

Fig. 9 One-dimensional model of the horizontally layered site

292

293

294

295

296

297

298

299

300

301

302

The propagation of seismic waves between soil layers can be considered as fluctuations in non-uniform media. After the seismic waves are incident vertically from bedrock to soil layers, they are refracted and reflected in different soil layers and finally arrive at the ground surface. The propagation process within the soil layers is influenced by the properties of soil layers, mainly the shear wave velocity structure, thickness, density, damping ratio and other factors (Yuan and Tian 2012; Liao 2002). In the 1D wave propagation theory, the overlying soil layer is simplified to a model that the mechanical properties vary vertically. At the same time, the underlying bedrock is regarded as a transversely homogeneous semi-infinite space. In addition, we assume that the seismic waves input from bedrock is a vertically incident $S H$ wave. According to the wave propagation theory, compared with other wave 
types (such as $S V-P$ wave conversion), the wave type conversion does not occur during the propagation of $S H$ waves in the soil layer (Yuan and Tian 2012).

Let the wave amplitude vector $\mathrm{Hn}$ of a simple harmonic wave incident vertically from the bedrock to the nth soil layer be:

$$
H_{n}=\left[\begin{array}{l}
E_{n} \\
F_{n}
\end{array}\right]
$$

Then the conversion relationship of the wave amplitude coefficients when propagating between the $n$th and $n+1$ st layers can be expressed as follows:

$$
H_{n+1}=T_{n} H_{n}, n=1,2, \cdots, N-1 \text {. }
$$

where $T_{n}$ is the transfer matrix between adjacent soil layers (Liao 2002):

$$
T_{n}=\left[\begin{array}{ll}
\frac{1+\alpha_{n}}{2} e^{i K_{n} h_{n}} & \frac{1-\alpha_{n}}{2} e^{-i K_{n} h_{n}} \\
\frac{1-\alpha_{n}}{2} e^{i K_{n} h_{n}} & \frac{1+\alpha_{n}}{2} e^{-i K_{n} h_{n}}
\end{array}\right]
$$

where $\alpha_{n}=\frac{\rho_{n} c_{n}}{\rho_{n+1} c_{n+1}}$ is the wave impedance, $K_{n}=\frac{\omega}{c_{n}}$ is the wavenumber, $\rho_{n}, c_{n}, \rho_{n+1}, c_{n+1}$ are the density and shear wave velocity of the medium in the nth and $n+1$ th layers, respectively, and $\omega=2 \pi f$ is the circular frequency of the incident harmonics. From equations (12), (13), and (14), the nth to the first layer transfer matrix $\bar{T}_{n}$ is obtained from equation (15):

$$
\bar{T}_{n}=T_{n-1} T_{n-2} \cdots T_{1} T_{0}=\left[\begin{array}{ll}
t_{11} & t_{12} \\
t_{21} & t_{22}
\end{array}\right]
$$

where $T_{0}$ is the unit matrix, so that $e_{n}=t_{11}+t_{12}$ and $f_{n}=t_{21}+t_{22}$ represent the nth layer incident and reflected wave amplitude coefficients, respectively, then the wave amplitude theoretical transfer function (TTF, amplification factor) from the surface (top of the first layer) to the top of the nth layer can be calculated according to the equation (16):

$$
\operatorname{TTF}(f)=\frac{e_{1}+f_{1}}{e_{n}+f_{n}}=\frac{2}{e_{n}+f_{n}}
$$

In this paper, we consider the linear hysteresis damping effect of the soil layer, $K_{n}$ in equation (14) is replaced by the complex wavenumber $K_{n}^{*}=\left(1-\lambda_{n} i\right) K_{n}, c_{n}$ is replaced by the complex shear wave velocity $c_{n}^{*}=\left(1+\lambda_{n} i\right) c_{n}, \lambda_{n}$ is the damping ratio and takes the value of 0.05 , and the $\operatorname{density}\left(\rho_{s}\right.$, unit: $\left.10^{3} \mathrm{~kg} / \mathrm{m}^{3}\right)$ uses the empirical formula proposed by Wang et al. (2018): $\rho_{s}=0.914 c_{n}^{0.122}$.

\subsection{The TTF of the MYGH10 Station}

The drilling depth of the MYGH10 station is $205 \mathrm{~m}$, and the detailed drilling data are shown in Table 2. Fig. 10 shows the wave velocity structure of the station along the depth direction, and the TTF of $P$ - and $S$-wave are obtained according to equation (16) (see Fig. 11).

Table 2 MYGH10 station drilling data

\begin{tabular}{cccccc}
\hline No. & Thickness $(\mathrm{m})$ & Density $\left(10^{3} \mathrm{~kg} / \mathrm{m} 3\right)$ & Depth $(\mathrm{m})$ & $\mathrm{V}_{\mathrm{P}}(\mathrm{m} / \mathrm{s})$ & $\mathrm{V}_{\mathrm{S}}(\mathrm{m} / \mathrm{s})$ \\
\hline 1 & 1.00 & 1.67 & 1.00 & 500.00 & 110.00 \\
2 & 2.00 & 1.79 & 3.00 & 1750.00 & 250.00 \\
3 & 31.00 & 1.89 & 34.00 & 1750.00 & 390.00 \\
4 & 80.00 & 1.99 & 114.00 & 1830.00 & 590.00 \\
5 & 91.00 & 2.06 & 205.00 & 1920.00 & 770.00 \\
\hline
\end{tabular}


Note: the density was calculated from $V_{S}$ using the empirical relation of Wang et al. (2018)

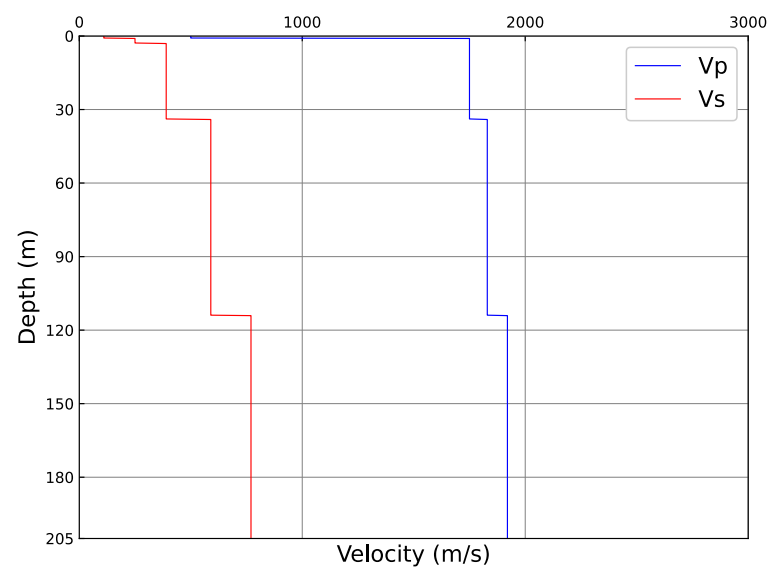

Fig. $10 P$ - and $S$-wave velocity structure of the MYGH10 station

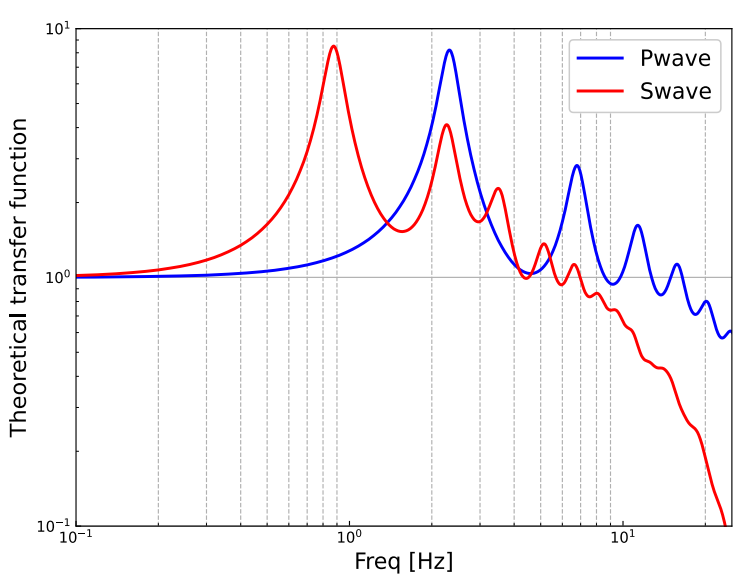

Fig. $11 P$-and $S$-wave theoretical transfer functions of the MYGH10 station

\section{Site Nonlinear Response Analysis on MYGH10 Station}

338 During strong earthquakes, seismic waves travelling towards the ground surface alter the soil layers' engineering characteristics and consequently the characteristics of travelling seismic waves also change concerning their frequency and amplitude contents (Tönük et al. 2014). The mechanism behind the nonlinear behaviour of the site under strong motion is relatively complicated. For the same site, the degree of nonlinearity among different soil layers will be different. The degree of nonlinearity will be more different for different sites even under the same ground motion intensity. Idriss and Seed (1968) and Wen et al. (1995) suggested that the nonlinear response in the near-surface sediment layer is generally manifested as the increase of soil damping and the decrease of shear wave velocity $V_{S}$ of the soil layer. According to the formula $f=V_{S} /(4 H)$ for estimating the predominant frequency of the soil layer, the magnitude of the predominant frequency $f$ is related to $V_{\mathrm{S}}$ and the thickness $H$ of the soil layer (Roca et al. 2008). When $V_{S}$ decreases, the value of $f$ will also decrease. Therefore, when the nonlinearity occurs in soil, the predominant frequency will be shifted leftward and become smaller in the spectral ratio curve. On the contrary, the increase of soil damping will enhance the soil viscosity. Then part of the soil layer acts as a giant "natural damper," which plays a role in damping and isolation, thus weakening the amplification effect of ground motion. Wen (1994) used several methods to study the nonlinear response of the soil, which showed that the shear modulus (or shear wave velocity) of the soil decreases with the increase of the ground motion amplitude.

Yuan and Tian (2012) also agreed that under the action of strong ground motions, the stiffness of the soil would decrease with the increase of strain, while the damping will increase; that is, the stress-strain of the soil medium has a nonlinear relationship. When the shear wave velocity of the soil layer decreases, the predominant period becomes longer, and the impedance ratio between the upper and lower soil layers becomes smaller, which ultimately leads to an increase in the amplification of the soil layer. However, the increase in damping has the opposite effect, which makes the amplification effect diminish.

$\mathrm{Yu}$ et al. (1993) proposed that the results were then applied by Wen et al. (1995), the spectral ratio of surface-to-input motion decreases near the dominant frequency of the soil, and the nonlinear characteristics of the site can be analyzed by dividing the frequency into 
three frequency bands: the low-frequency band, the central frequency band, and the highfrequency band, and it is believed that in the low-frequency band the wavelength of seismic waves is long enough that the spectral ratio will not be affected by the nonlinearity too much. In the high-frequency band, inversely, compared with the Fourier amplitude spectral ratio factor of weak ground motion, that of the strong ground motion is obviously "overamplified," and this "over-amplification" is explained as a result of the competition between increased damping and higher harmonics generation when nonlinearity occurs, finally, in the central frequency band, the spectral ratio decreased, and the resonant frequency shifts leftward and becomes smaller (Yu et al. 1993; Wen et al. 1995).

Wen et al. (2006) proposed using the HVSR method to identify nonlinear soil response and used the SBSR method to verify the reliability of HVSR when identifying soil nonlinearity. The two spectral ratio methods can reach consistent conclusions. Satoh et al. (2014) studied the influence of site on the large motions by inverting the soil layer's structure and simulating ground motions considering the soil nonlinearity, and they found that the nonlinearity of the soil on large motions results in the reduction of the amplification factor by half compared with those in the linear regime; they also studied the impact time of nonlinearity by comparing the PGA of aftershocks and pointed out that the time of soil returning to linear state varies from site to site. This paper will judge the recovery of nonlinearity by comparing the spectral ratio curve of aftershocks records.

Jin et al. (2004) proposed a time-domain nonlinear analysis method for calculating the seismic response of horizontally layered sites. They investigated the nonlinear response of horizontally layered sites under strong ground motions. The results showed that the soil response tends to decrease amplitude in the spectral ratio curve and shift fundamental frequency toward a long period as the input ground motions increase. Luo et al. (2019) found that with the increase of PGA, the dominant frequencies obtained by HVSR tended to shift to lower frequencies from higher frequencies. We summarized the results of the above studies, and the nonlinear site response can be reified by the characteristics of spectra ratio curves, as follows:

(1) Compared to the dominant frequency of the weak ground motions spectral ratio curves, the strong ground motions in the spectral ratio curve are shifted leftward to become smaller.

(2) The decrease of impedance ratio between soil layers and the increase of soil damping produces the opposite effect. These two effects determine the overamplification, deamplification, or equal amplification of the strong ground motions relative to the weak motions in a specific frequency band (Wen et al. 1995).

In this paper, we analyzed the nonlinear response that occurs at the site-specific MYGH10 station site under the effect of strong ground motions based on the conclusions obtained from the above study. Fig. 12 shows the spectral ratio curves of weak ground motion records (see Fig. 12a), strong ground motion records (see Fig. 12b) and mainshock records (see Fig.12c), which are compared with the TTF, respectively. Fig. 12a,b shows that the TTF is slightly smaller than the spectral ratio of weak and strong ground motion records in $0.1 \sim 0.5 \mathrm{~Hz}$. The spectral ratio in $0.6 \sim 1.3 \mathrm{~Hz}$ and $2.0 \sim 2.6 \mathrm{~Hz}$ are overall suppressed and abated compared with the TTF, especially in the vicinity of $0.9 \mathrm{~Hz}$. However, the spectral ratio is overall overamplified after $2.8 \mathrm{~Hz}$. In Fig. 12c, it is more evident that the amplification presented by the red SBSR curve of mainshock records is overall overamplified after about $1.2 \mathrm{~Hz}$. These phenomena are almost consistent with the results of $\mathrm{Yu}$ et al. (1993) mentioned above.

414 


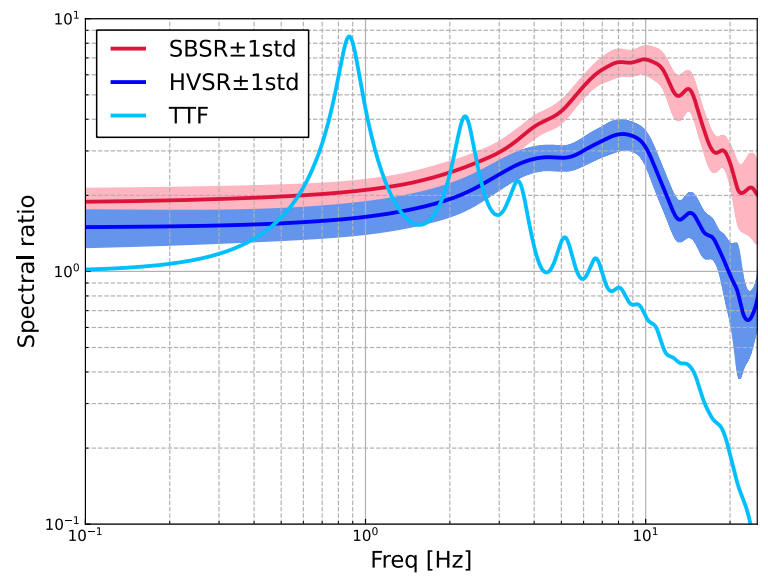

(a) $\mathrm{PGA}<100$ gal vs. TTF

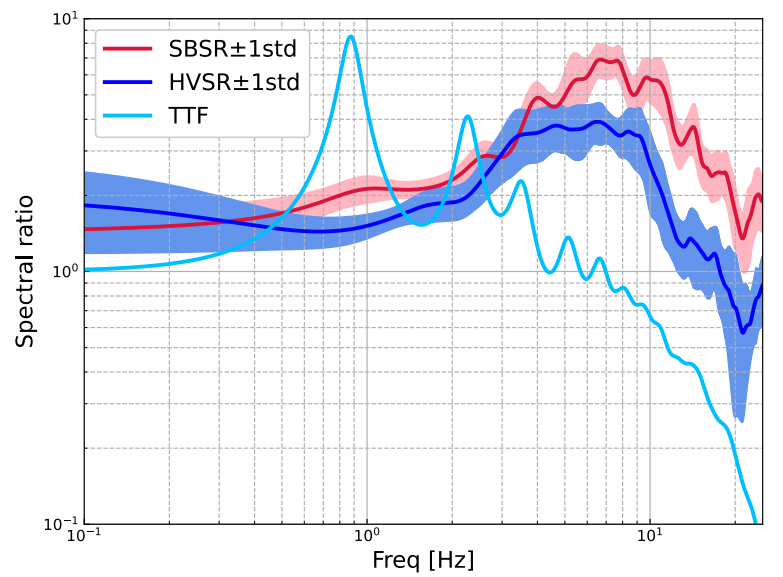

(b) PGA>100 gal vs. TTF

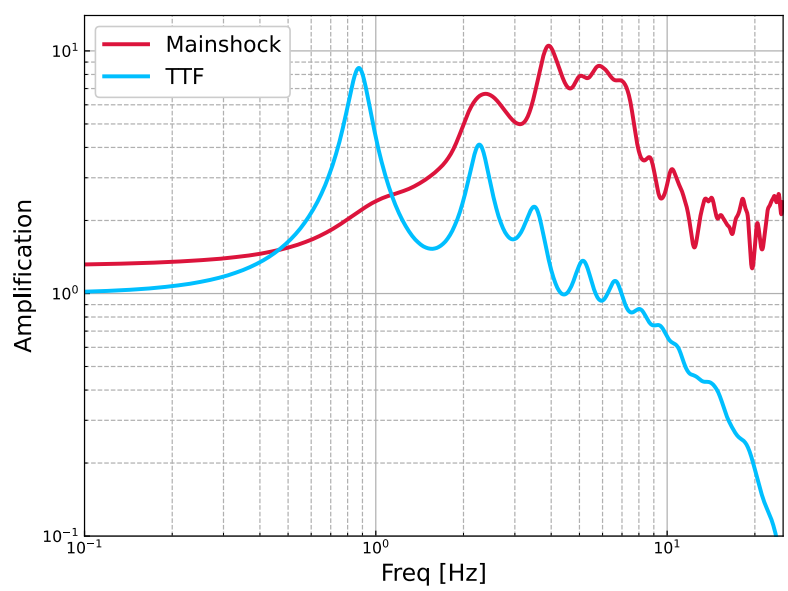

(c) SBSR of mainshock records vs. TTF

Fig. 12 Comparison of theoretical transfer functions and spectral ratio curves for three types of earthquake events with different intensities (weak ground motions (a), strong ground motions (b), and the Fukushima mainshock (c)). The solid red and blue lines represent the average spectral ratio curves of historical weak and strong ground motion records, and the widths of the spectral ratio curves represent \pm one standard deviation $(1 \mathrm{std})$

Fig. 13 shows the differences between the average spectral ratio curve (the blue curve) of the weak ground motion records from March to June after the Fukushima mainshock and the spectral ratio curve (the green curve) of the mainshock records, compared with the average spectral ratio curve (the red curve) of the historical weak ground motion records (PGA <100 gal) before the Fukushima earthquake. As is shown, Fig. 13a is the curves of HVSR, and Fig. $13 \mathrm{~b}$ is the curves of SBSR. We found that whether it is HVSR or SBSR curve, the green curve has an apparent overall left shift phenomenon compared with the red curve. The site's amplification factor under weak ground motions shown by the red curve in Fig. 13b shows a peak amplitude of about seven at the predominant frequency of $10 \mathrm{~Hz}$, but the predominant frequency decreased to approximately $3.8 \mathrm{~Hz}$ in the green curve; in addition, the peak amplitude at the frequency of $10 \mathrm{~Hz}$ is reduced to about 3 in the green curve because of the soil nonlinearity. 


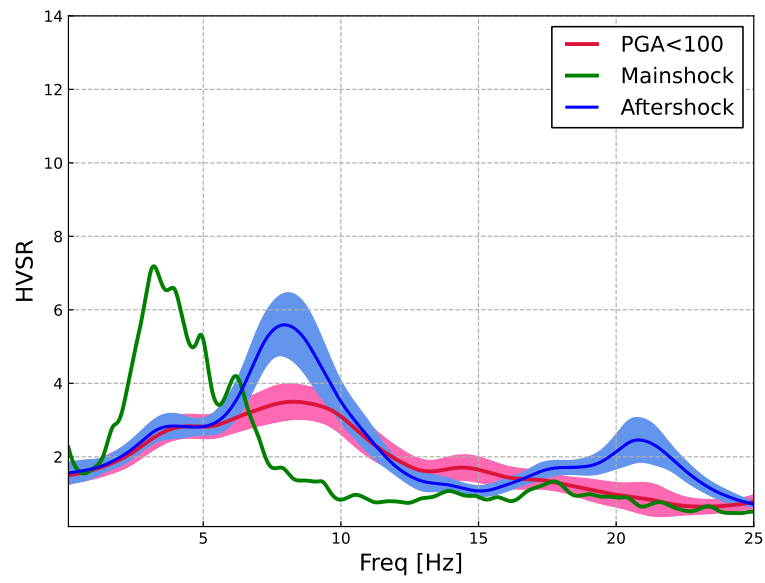

(a)

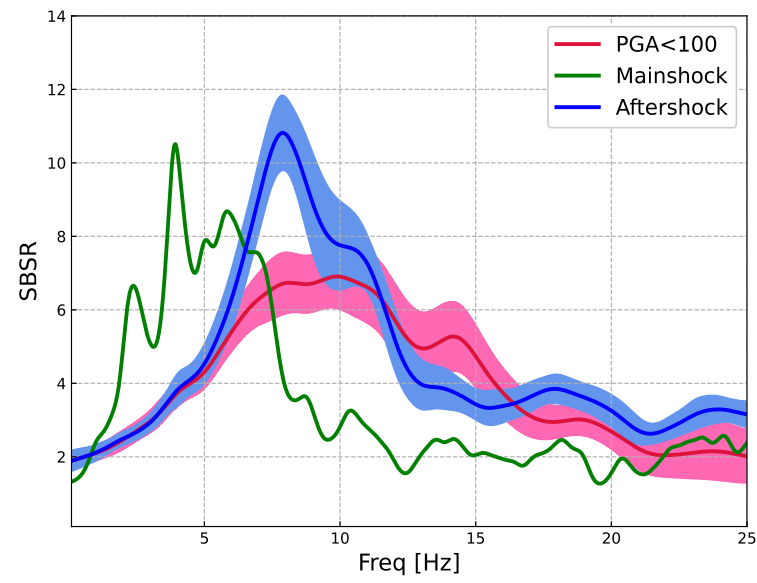

(b)

Fig. 13 Comparison of HVSR (a) and SBSR (b) spectral ratio curves for three types of ground motion records. The solid red and blue lines represent the average spectral ratio curves of historical weak ground motion and the Fukushima aftershocks records (March to June after the mainshock), respectively, and the solid green lines represent the spectral ratio curves of the Fukushima mainshock record. The widths of the spectral ratio curves represent \pm one standard deviation (1std)

In Fig. 13a and Fig. 13b, the spectra ratio is overamplified within $1 \sim 7 \mathrm{~Hz}$, while the amplification is weakened in the subsequent frequency band from 7 20 Hz compared with the weak ground motions, and the spectral ratio curve after $20 \mathrm{~Hz}$ is closer to that of the weak ground motions. The spectral ratio curves are closer after $20 \mathrm{~Hz}$, which means that the nonlinearity in the higher frequency band has little effect on the amplification of the site. The blue curve shows that the nonlinearity caused by the strong motions has alleviated, as shown by the fact that the red and blue curves in general overlap in the frequency band $0.1 \sim 6 \mathrm{~Hz}$, and the predominant frequency of site recovers from $3.8 \mathrm{~Hz}$ to about $7 \sim 8 \mathrm{~Hz}$, but the amplification in the dominant frequency region keeps still more significant than that of the red curve. We can observe that both the HVSR and SBSR curves can give relatively consistent conclusions in identifying the nonlinear site response, which is consistent with the study results of Wen et al. (2006); in contrast, the HVSR gives a smaller value in the estimation of the site amplification.

The blue curves in Fig. 14 show the average spectral ratio curves of the 16 aftershocks records (PGA in the range of 4.0 gal to 97.2 gal and epicentre distance from $63 \mathrm{~km}$ to 183 $\mathrm{km}$ ) that occurred within three days after the Fukushima mainshock. We found the tiny discrepancy between Fig. 13 and Fig. 14 and can draw the same conclusion, which means that after the Fukushima mainshock, the MYGH10 station site returned to its previous state in a short time. 


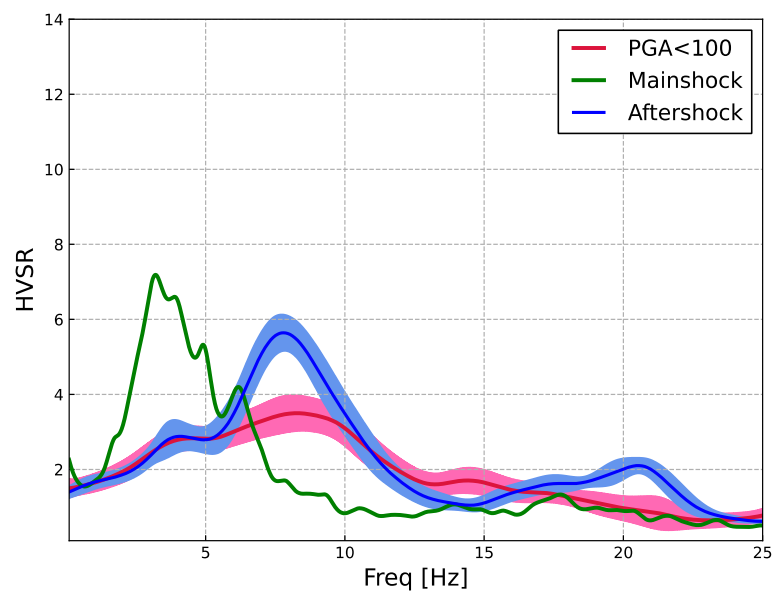

(a)

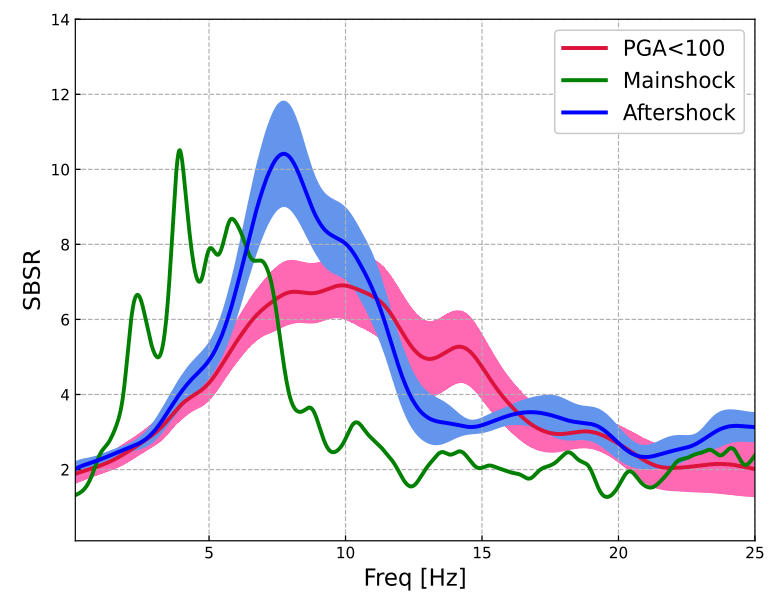

(b)

Fig. 14 Comparison of the HVSR (a) and SBSR (b) spectral ratio curves for three types of earthquakes (the red and green curves are same with that in Fig. 13). The solid blue lines represent the average spectral ratio curves of the Fukushima aftershocks records (within three days after the mainshock). The widths of the spectral ratio curves represent \pm one standard deviation (1std)

\section{Conclusions and Discussion}

In this artical, the HVSR method is described in detail, and the seismic response of the MYGH10 station is analyzed by spectral ratio method and theoretical transfer function, and the following conclusions are drawn:

(1) The two hypothesis of the "Nakamura" method under strong and weak ground motions are discussed and analysed by using the records of the MYGH10 station, and the results show that the first hypothesis is valid, that is, the propagation of seismic waves at bedrock is even in all directions (i.e. $H V S R_{B}=1$ ). Nevertheless, the second hypothesis fails to be accurate; there is a phenomenon of amplification of seismic $P$-wave in the highfrequency band. Moreover, we found that the difference in vertical amplification of $P$-wave under weak and strong ground motions is slight. Furthermore, underestimation occurs when using HVSR for $S$-wave horizontal amplification estimation, so HVSR cannot be used directly for amplification estimation of the site and requires additional correction but can estimate predominant frequency.

(2) The HVSR method can be used instead of the SBSR method to identify nonlinear site responses and analyze nonlinear characteristics, so for stations without vertical arrays, we can use HVSR.

(3) By comparing the two spectral ratio curves of strong and weak motions with the TTF of the MYGH10 station, we found that the amplification difference in the low-frequency band is slight, and the amplification decreases in the central frequency band. At the same time, the over-amplification phenomenon occurs in the high-frequency band.

(4) We found nonlinear behaviour in the MYGH10 station under the Fukushima mainshock, mainly manifested by the decrease of the site's predominant frequency from $\sim 10 \mathrm{~Hz}$ to $\sim 3.8 \mathrm{~Hz}$, the increase of the amplification factor from 7 to more than 10 . After the Fukushima mainshock, the site's predominant frequencies, in general, returned to the original positions, except for the amplification factors at the predominant frequencies, which were still overamplified. However, the amplification factors of the other frequency bands are 
generally restored to the level of weak ground motions, indicating that the site nonlinearities were alleviated.

However, in this study, the unbalanced number of weak and strong ground motion records may bring unavoidable errors to the analysis. Beyond that, the limitations of the TTF model itself and the $V s$ variability, also known as "aleatory variability and epistemic uncertainty" (Zhu et al. 2020b), will inevitably lead to the discrepancies between the TTF and ETF (Teague et al. 2018). Regarding the nonlinear response at the MYGH10 station, the inversion method can be used in the subsequent research to obtain the shear velocity structure of the site under strong motion and compare it with the borehole data to get the specific nonlinear characteristics of the site along the depth direction.

\section{References}

Beresnev I A, Wen K L (1996) Nonlinear soil response-A reality? Bull Seism Soc Am 86(6): 1964-1978. https://doi.org/10.1785/BSSA0860061964

Ducellier A, Kawase H, Matsushima S (2013) Validation of a New Velocity Structure Inversion Method Based on Horizontal-to-Vertical (H/V) Spectral Ratios of Earthquake Motions in the Tohoku Area, Japan. Bull Seism Soc Am 103(2A):958-970. https://doi.org/10.1785/0120120214

Idriss I M, Seed H B (1968) An analysis of ground motions during the 1957 San Francisco earthquake. Bull Seism Soc Am 58(6):2013-2032. https://doi.org/10.1785/BSSA0580062013

Jin Xing, Kong Ge, Ding Haiping (2004) Nonlinear seismic response analysis of horizontal layered site. Earthquake Engineering and Engineering Dynamics 24(3):38-43 (in Chinese)

JI Kun, REN Yefei, WEN Ruizhi (2017) Review on site classification with spectral ratio method. World Earthquake Engineering 33(1):91-99 (in Chinese)

Kawase H, Sanchez-Sesma F J, Matsushima S (2011) The Optimal Use of Horizontal-to-Vertical Spectral Ratios of Earthquake Motions for Velocity Inversions Based on Diffuse-Field Theory for Plane Waves. Bull Seism Soc Am 101(5):2001-2014. https://doi.org/10.1785/0120100263

Kawase H, Nagashima F, Nakano K et al (2018) Direct evaluation of S-wave amplification factors from microtremor H/V ratios: Double empirical corrections to "Nakamura" method. Soil Dyn Earthq Eng 126(105067). https://doi.org/10.1016/j.soildyn.2018.01.049

Lermo J F, Chavez-Garcia F J (1993) Site effect evaluation using spectral ratios with only one station. Bull Seism Soc Am 83(5):1574-1594. https://doi.org/10.1785/BSSA0830051574

Liao Zhenpeng (2002) Introduction to wave motion theories in engineering, 2nd edn. Science Press, Beijing, pp 49-59 (in Chinese)

LI XiaoJun, Rong MianShui, YU Yan (2020) Inversion for velocity structure of soil layers by seismic acceleration records. Chinese J Geophys (in Chinese) 63(1):236-246. https://doi.org/10.6038/cjg2020M0491

Luo Guichun, LI Xiaojun, Fu Lei et al (2019) Study on Nonlinearity of Site Effect with the HVSR Spectral Ratio. Journal Of Seismological Research 042(4):546-554 (in Chinese)

Moro G D (2014) Horizontal-to-Vertical Spectral Ratio. In: Surface Wave Analysis for Near Surface Applications, Chapter 4, Elsevier, pp 81-85. http://dx.doi.org/10.1016/B978-0-12-8007709.00004-2

Nagashima F, Matsushima S, Kawase H et al (2014) Application of Horizontal-to-Vertical Spectral Ratios of Earthquake Ground Motions to Identify Subsurface Structures at and around the K-NET Site in Tohoku, Japan. Bull Seism Soc Am 104(5):2288-2302. https://doi.org/10.1785/0120130219

Nakamura Y (1989) A method for dynamic characteristics estimation of subsurface using microtremor on the ground surface. Q Rep Railway Tech Res Inst 30:25-33

Nakamura Y (2019) What Is the Nakamura Method? Seismol Res Lett 90(4):1437-1443. https://doi.org/10.1785/0220180376

Parolai S (2004) The Importance of Converted Waves in Comparing H/V and RSM Site Response Estimates. Bull Seism Soc Am 94(1):304-313. https://doi.org/10.1785/0120030013

Roca A., Oliveira C.S., Ansal A., Figueras S. (2008) Local Site Effects and Microzonation. In: Oliveira C.S., Roca A., Goula X. (eds) Assessing and Managing Earthquake Risk. Geotechnical, Geological And Earthquake Engineering, vol 2. Springer, Dordrecht. https://doi.org/10.1007/978-1-4020-3608-8_4 
Rong Mianshui, Li-Yun Fu, Zhenming Wang et al (2017) On the Amplitude Discrepancy of HVSR and Site Amplification from Strong-Motion Observations. Bull Seism Soc Am 107(6):2873-2884. https://doi.org/10.1785/0120170118

Rong M S, FU L Y, Li X J (2018) Inversion of site velocity structure using a hybrid global optimization algorithm based on HVSRs of accelerograms recorded by a single station. Chinese $\mathbf{J}$ of Geophys (in Chinese) 61(3):938-947. https://doi.org/10.6038/cjg2018L0171

Satoh T, Hayakawa T, Oshima M et al (2014) Site Effects on Large Ground Motions at KiK-net Iwase Station IBRH11 during the 2011 Tohoku Earthquake. Bull Seism Soc Am 104(2):653-668. https://doi.org/10.1785/0120130095

Teague DP, Coxb BR, Rathje EM. (2018) Measured vs. predicted site response at the Garner Valley Downhole Array considering shear wave velocity uncertainty from borehole and surface wave methods. Soil Dyn Earthq Eng 113:339-355. https://doi.org/10.1016/i.soildyn.2018.05.031

Tönük, G., Ansal, A., Kurtuluş, A. et al (2014) Site specific response analysis for performance based design earthquake characteristics. Bull Earthquake Eng 12:1091-1105. https://doi.org/10.1007/s10518-0139529-1

Wang SY, Shi Y, Jiang WP et al (2018) Estimating site fundamental period from shear-wave velocity profile. Bull Seism Soc Am 108(6):3431-3445. https://doi.org/10.1785/0120180103

Wen K L (1994) Non-linear soil response in ground motions. Earthq Eng Struct Dyn 23(6):599-608. https://doi.org/10.1002/eqe.4290230603

Wen K L, Beresnev I A,Yeh Y T (1995) Nonlinear soil amplification inferred from downhole strong seismic motion data. Geophys Res Lett 21(24):2625-2628. https://doi.org/10.1016/0148-9062(95)93292-W

Wen K L, Chang T M, Lin C M et al (2006) Identification of Nonlinear Site Response Using the H/V Spectral Ratio Method. Terr Atmos Ocean Sci 17(3):533-546

Yamazaki F, Ansary M A (1997) Horizontal-to-vertical spectrum ratio of earthquake ground motion for site characterization. Earthq Eng Struct D 26(7):671-689. https://doi.org/10.1002/(SICI)10969845(199707)26:7<671::AID-EQE669>3.0.CO;2-S

Yu G, Anderson J G, Siddharthan R A J (1993) On the characteristics of nonlinear soil response. Bull Seism Soc Am 83: 218-244. https://doi.org/10.1785/BSSA0830010218

Yuan Yifan, Tian Qiwen (2012) Engineering Seismology. Seismological Press, Beijing, pp 270-295 (in Chinese)

Zhao J X, Irikura K, Zhang J et al (2004) Site classification for strong-motion stations in Japan using H/V response spectral ratio. In: 13th World Conference on Earthquake Engineering, Vancouver, B.C., Canada, Paper No. 1278

Zhu C, Cotton F, Pilz M (2020a) Detecting Site Resonant Frequency Using HVSR: Fourier versus Response Spectrum and the First versus the Highest Peak Frequency. Bull Seism Soc Am 110 (2): 427-440. https://doi.org/10.1785/0120190186

Zhu C, Pilz M, Cotton F (2020b) Evaluation of a Novel Application of Earthquake HVSR in Site-Specific Amplification Estimation. Soil Dyn Earthq Eng 139(106301). https://doi.org/10.1016/j.soildyn.2020.106301

\section{$570 \quad$ Statements and Declarations}

571 Funding This research was funded by Scientific Research Fund of Institute of Engineering 572 Mechanics, China Earthquake Administration (Grant No. 2016A03), National Key Research 573 and Development Program of China (Grant No. 2017YFC1500802), and National Natural 574 Science Foundation of China (Grant No. U2039209, 5150082083).

575 Competing Interests The authors declare that they have no conflict of interest or competing 576 interests.

577 Author Contributions D.W. Tao and S.L. Zhang conceived the idea of the study; S.L. 578 Zhang performed the research, analysed data, and wrote the initial draft of the paper; D.W. 579 Tao, Q. Ma and Q.C. Xie put forward valuable opinions for this study and contributed to the 
580 revisions; F.C. Wang provided the initial procedure of TTF for this study. All authors 581 discussed the results and revised the manuscript.

582 Data Availability All data in this study were from the KiK-net website of the National

583 Institute of Disaster Prevention Science and Technology (NIED)

584 (https://www.kyoshin.bosai.go.jp/). 